\title{
Constitutive Rules, Language, and Ontology
}

\author{
Frank Hindriks
}

Received: 19 November 2007/ Accepted: 11 May 2009/Published online: 30 May 2009

(C) The Author(s) 2009. This article is published with open access at Springerlink.com

\begin{abstract}
It is a commonplace within philosophy that the ontology of institutions can be captured in terms of constitutive rules. What exactly such rules are, however, is not well understood. They are usually contrasted to regulative rules: constitutive rules (such as the rules of chess) make institutional actions possible, whereas regulative rules (such as the rules of etiquette) pertain to actions that can be performed independently of such rules. Some, however, maintain that the distinction between regulative and constitutive rules is merely a linguistic one. In this paper I present the status account of constitutive rules in order to address this criticism. According to the status account constitutive rules pertain to institutional statuses and statuses are to be understood in terms of status rules. Status rules concern the enabling and constraining roles of institutions, and constitutive rules specify the preconditions that have to be met in order for them to play these roles. Even though I end up endorsing the claim that the distinction mentioned is a linguistic one, I go on to argue that there is an underlying reality that constitutive rules serve to make apparent.
\end{abstract}

It is a commonplace within philosophy that institutions can be understood in terms of constitutive rules. Proposals for understanding particular institutional phenomena or institutions generally in terms of such rules have been made by, among others, Rawls (1955), Midgley (1959), Searle (1969, 1995), and Goldman (1970). Searle's account of constitutive rules is perhaps the most developed one, and it remains the main point of reference in the contemporary literature on the subject. Over the years, however, it has attracted severe criticism (Ransdell 1971; Warnock 1971; Giddens 1984; Ruben 1997). As we shall see below, it has been argued, inter alia,

\footnotetext{
F. Hindriks $(\square)$

Faculty of Philosophy, Department of Ethics, University of Groningen, Oude Boteringestraat 52, 9712 GL Groningen, The Netherlands

e-mail: f.a.hindriks@rug.nl
} 
that constitutive rules do not capture the essence of institutional phenomena, that all rules are constitutive, and that the difference between constitutive rules and regulative rules, to which Searle contrasts them, is merely linguistic rather than ontological. Nevertheless, the notion continues to be used in fields as diverse as the philosophy of language (Lewis 1983a; Williamson 1996; Gluër and Pagin 1999), the philosophy of law (MacCormick and Weinberger 1986; Ruiter 1997), and most recently artificial intelligence (Jones and Sergot 1997; Boella and Van Der Torre 2004; Grossi et al. 2006). Although partial answers to some of these criticisms have been proposed, there is as yet no comprehensive theory of constitutive rules that answers all or even the most pressing ones. In light of the continuing significance of the notion we need a better understanding of what constitutive rules are.

In this paper I propose what I call 'the status account of constitutive rules'. It provides answers to the main criticisms directed at Searle's account, which I call 'the conventional generation account' for reasons provided below. According to the status account, constitutive rules pertain to institutional statuses, such as money, and statuses are to be understood in terms of status rules, e.g. 'money is a means of exchange'. Status rules concern the enabling and constraining roles of institutions, and constitutive rules specify the preconditions that have to be met in order for them to play these roles. As such, they reveal the way in which institutions affect the parameters of social interaction. Consider, for instance, the impact property rights have on the normative relations that obtain between us. They restrict the use of goods to particular people. This can be captured in terms of status rules. Constitutive rules, on the other hand, specify the conditions that have to be met within a particular context for a particular kind of entity to have a certain status. In some contexts, all you have to do in order to become the owner of a piece of land is to (be the first to) claim it as your own, whereas in many other contexts you have to go through far more complex procedures. Even though the claim that the distinction between regulative and constitutive rules is a linguistic one is confirmed in this paper, it turns out that there is an underlying reality that constitutive rules serve to make explicit. I argue, however, that their ontological significance can only be properly appreciated once they are complemented with status rules.

\section{The Conventional Generation Account of Constitutive Rules}

When he introduced his account of constitutive rules, John Searle relied on insights propounded by Elisabeth Anscombe and John Rawls (see his 1964, p. 55, n6 and $\mathrm{n} 7$ ). Both of them emphasized the fact that certain things can only exist in virtue of institutions. Anscombe distinguished between brute facts and facts that presuppose an institutional setting. She noted, for instance, that adequately describing an act as 'sending a bill' presupposes the institution of buying and selling (Anscombe 1981 [1958], p. 24). Her view is that the fact that someone sends a piece of paper is a brute fact relative to the fact that someone sends a bill. The former can only properly be regarded as the latter if the institutional context is appropriate. Rawls distinguished rules we follow only because of their utility in particular cases, such as rules of thumb, from rules that define practices or institutions. Whereas he took 
the former to be generalizations from decisions taken in the past, rules of the latter kind are logically prior to the acts that fall under them. An act cannot be described as an institutional act if the rules of the relevant institution are not in place. For instance, an act can only be adequately described as an act of stealing a base if the rules that constitute baseball apply (Rawls 1955, p. 25).

Searle $(1964,1969,1995)$ uses the term 'constitutive rule' for rules that define institutional activities. He draws a contrast between constitutive and regulative rules in terms that are reminiscent of Rawls. Regulative rules pertain to activities that are logically independent of the rules, whereas activities that fall under constitutive rules logically depend on them. In line with this, Searle writes:

[R] egulative rules regulate antecedently or independently existing forms of behaviour [...]. But constitutive rules do not merely regulate, they create or define new forms of behaviour. The rules of football or chess, for example [...] create the very possibility of playing such games. (1969, p. 33).

According to Searle, constitutive rules define and create (the possibility of) institutional forms of behavior (see also ibid., p. 35 and 2007, p. 88). The underlying conception of institutions is that they are (systems of) constitutive rules (ibid., p. 51; 1995, p. 140). Inspired by Anscombe, Searle holds that facts that exist independently of institutions are brute facts. Institutional facts, such as the fact that the United States started a war against Iraq, presuppose institutions- the institution of war, among others - and, hence, they presuppose constitutive rules.

Searle also takes the form, or syntax, as I prefer to call it, of constitutive rules to be different from that of regulative rules. With respect to the latter Searle maintains that "[r]egulative rules characteristically have the form or can be comfortably paraphrased in the form "Do $X$ " or "If $Y$ do $X$ ", (1969, p. 34). The idea appears to be that regulative rules indicate obligations we have, which can be expressed linguistically by means of imperatives. (Obligations can be expressed in other ways, but regarding this one formulation of them as canonical is useful for the purpose of characterizing the distinction between the two kinds of rules at issue.) Searle takes the syntax of constitutive rules to be ' $X$ counts as $Y$ in context $C$ '. He refers to this as 'the counts-as locution'. This locution reveals that constitutive rules do not indicate the presence of obligations. The locution can be used for illustrating the point made about logical (in)dependence. Acts of type $X$ are possible independently of the rule that regulates them. For example, sending out an invitation to a party two weeks in advance is possible independently of a rule of etiquette that might be in force according to which one must do so (ibid., p. 35). Acts of type $Y$, such as scoring a touchdown, cannot be performed in the absence of a constitutive rule that defines such acts. Note that, in addition to actions, the counts-as locution can also be applied to objects, persons, and events. A certain piece of paper, for instance, can count as money in a particular context, and it would not be money if it were not for the underlying constitutive rule.

Searle said little about the phrase 'counts as' that occurs in the counts-as locution in his early work. The phrase indicates that the actions derive their character from the institutional setting in which they occur, including the group of people who sustain the relevant institution. It is always a group of people that counts something 
as something else insofar as institutional phenomena are concerned. Institutional settings presuppose (sufficient) agreement about the rules that make up institutions. Searle introduced the term 'collective acceptance' as a technical term for agreement in his more recent work, in particular in his book The Construction of Social Reality (1995). Relying for the time being on an intuitive understanding of what agreement or collective acceptance is, we should note that the role played by collective acceptance in Searle's recent work is intimately related to the phrase 'counts as'. Somewhat analogous to the syntax of constitutive rules, ' $X$ counts as $Y$ in $C$ ', Searle (1995, p. 44) now claims that institutions require that we collectively accept $X$ as $Y$. In Sect. 2.3 I propose an answer to the question how exactly the notion of collective acceptance can contribute to our understanding of the phrase 'counts as' as it appears in the counts-as locution.

In order to understand his conception of constitutive rules more fully, we need to consider two other notions Searle has introduced: status function and deontic power. Doing so will also prove to be valuable when developing an improved account of such rules-the status account of constitutive rules presented below. Status functions are institutional functions such as the function of money to serve as a means of exchange. The $Y$-terms that figure in the counts-as locution refer to status functions. Such functions can only be performed because we collectively accept that certain entities have them. Searle contrasts this to functions of artefacts that can be performed in virtue of the physical features of the objects to which they are assigned. A screwdriver, for instance, can be used for screwing a lock on a door because of its physical characteristics. In the case of institutional functions, however, the physical structure of the entities that have them is less crucial. Searle writes: 'In the extreme case, the status function may be attached to an entity whose physical structure is only arbitrarily related to the performance of the function.' (Ibid., p. 41).

Searle introduced the term 'deontic power' in order to conceptualize the normative dimension that many, if not all, institutions have. Deontic powers 'regulate relations between people' (ibid., p. 100). Searle distinguishes between positive and negative deontic power. Positive deontic power is a matter of enablement and involves rights. A president, for instance, may have the right to veto legislation and the person who holds the office is enabled by her role to do so. Negative deontic power pertains to requirements and obligations. Just like status functions, deontic powers also depend on collective acceptance. Searle has said little about how exactly terms that refer to deontic powers relate to the $Y$-terms that appear in constitutive rules. Below I introduce the notion of a status rule that is meant to complement that of a constitutive rule and that serves to clarify the relation between descriptive and normative features of institutions. This provides a somewhat different perspective on the way functions figure in constitutive rules. Furthermore, it serves to clarify how collectively accepting something as something else can have normative implications.

I shall call Searle's account of constitutive rules 'the conventional generation account'. The term 'conventional generation' is due to Goldman (1970), who argued that institutional actions are conventionally generated, by which he meant that actions such as signaling before making a turn, and checkmating one's opponent, 
exist in virtue of rules, conventions, or social practices. In the latter case, the relevant rules are the rules of chess. In the former case, Goldman suggests that the underlying rule is this: '[E]xtending one's arm out the car window while driving counts as signaling for a turn.' (Ibid., p. 25). He goes on to argue that in most instances of conventional generation there are circumstances that are essential for the performance of the institutional action. He mentions the positions of the various pieces on the chessboard and the fact that a particular person was driving a car when he extended his arm out of the window as illustrations of such circumstances. All these claims, in particular Goldman's view on the roles that rules and circumstances play in relation to institutional actions, are in agreement with what Searle says about constitutive rules. This raises the question whether Searle is, just as Goldman, mainly concerned with how institutional entities come into being, in spite of his more ambitious aim of providing an ontology of institutions per se. That Searle does not move substantially beyond an account of the way in which institutional entities are created seems to be implied by a more recent definition of institutions that he has provided: 'An institution is any collectively accepted system of rules (procedures, practices) that enable us to create institutional facts.' (2005, p. 21) In Sect. 2.2, we see that Ransdell's (1971) criticism of Searle can be interpreted in this light. My aim in this paper is to come to a distinctive appreciation of how constitutive rules contribute to our understanding of institutional phenomena, and how they are relevant to the normative relations that obtain between us. First, however, we need a better grip on the distinction between constitutive and regulative rules. As we saw above, this distinction plays a central role in Searle's characterization of constitutive rules. Below we shall see that the main challenge to be confronted is the criticism that this distinction is merely a linguistic one and has no ontological significance.

\section{The Status Account of Constitutive Rules}

\subsection{Constitutive and Regulative Rules}

Giddens (1984) argues that constitutive rules do not form a type of rules that is genuinely distinct from regulative rules. Instead, he maintains that all rules have both constitutive and regulative aspects. Consider the following rule: 'It is a rule that all workers must clock in at 8.00 a.m.' (Ibid., p. 19). Those who support the distinction between constitutive and regulative rules will maintain that this rule 'does not help define what work is: it specifies how work is to be carried on' (ibid., pp. 19-20). Therefore, it is merely a regulative rule which contrasts, for instance, with the rules that define checkmate. Giddens formulates his critique as follows:

I would say of (1) and (4) [the rules concerning checkmate and the one concerning work] that they express two aspects of rules rather than two variant types of rule. (1) is certainly part of what chess is, but for those who play chess it has sanctioning or 'regulative' properties; it refers to aspects of play that must be observed. But (4) has also constitutive aspects. It does not perhaps enter into the definition of what 'work' is, but it does enter into a concept like 
'industrial bureaucracy'. What (1) and (4) direct our attention to are two aspects of rules: their role in the constitution of meaning, and their close connection with sanctions. (1984, p. 20)

Giddens argues here that constitutive rules also regulate, and that regulative rules also play a constitutive role. ${ }^{1}$ Let us take a closer look at these claims in turn.

Searle (1969, p. 34) maintains that constitutive rules, or at least some of them, are non-imperative rules. This fits naturally with the following example that Searle provides of a constitutive rule: 'Bills issued by the Bureau of Engraving and Printing $(X)$ count as money $(Y)$ in the United States $(C)$.' $(1995$, p. 28$)$. On the face of it, this rule does not regulate anything. In particular, its formulation does not specify an obligation. Furthermore, it is not immediately clear what kind of sanctioning might be involved. The rule links the satisfaction of certain conditions to the applicability of an institutional term. This is a matter of classification rather than regulation. That constitutive rules do not regulate anything directly follows from their syntax. As we saw above, the syntax of constitutive rules is given by the counts-as locution, and this locution does not make any reference to obligations.

One could perhaps say that constitutive rules regulate our classificatory practices. Garcia (1987) suggests reading constitutive rules as implicit imperatives pertaining to classification. He argues that constitutive rules can be reconstructed as commands to count $X \mathrm{~s}$ as $Y \mathrm{~s}$. But this seems wrong. It is a fact that certain pieces of paper are collectively accepted as money. Taking it at face value the constitutive rule of money does not seem to be a norm. ${ }^{2}$ Now it might be that there are regulative rules concerning the way we use our terms. Given a regulative rule such as 'One must: use a term only if one applies it correctly', misapplication of a $Y$-term does involve a violation of a rule. If some such regulative rule is in force, counts-as rules do in effect set standards that can be violated, even though they do not themselves involve imperatives. The rule mentioned stipulates a condition that a piece of paper has to meet in order for it to be money in the United States (or, rather, it would do so if it contained a reference to the Federal Reserve instead of to the Bureau of Engraving and Printing). It follows that if someone claims that a piece of paper that meets this condition is not money, then she is making a mistake. And we do sometimes sanction people for such mistakes. The upshot of this line of thought is first, that constitutive rules do not regulate anything directly because they do not as such involve obligations, and second, that they play a regulative role indirectly, because when combined with regulative rules concerning the use of our terms they do entail obligations (see Tuomela 2002, pp. 172-73 and Tummolini and Castelfranchi 2006, p. 308 for similar claims; see note 9 for a further comment on this issue).

Giddens also claims that rules which Searle takes to be merely regulative have a constitutive aspect. As we saw above, he maintains that the rule 'All workers must

\footnotetext{
1 See Lagerspetz (1995) for a similar view. Lagerspetz claims: 'It seems that every rule called "regulative" by Searle has a constitutive aspect' (ibid., p. 18). Although he does not go so far as claiming that all constitutive rules also regulate, he argues that many do so.

2 Presumably this is why Searle says that 'it is not easy to see how one could even violate the rule as to what constitutes checkmate in chess, or touchdown in football' (1969, p. 41; see also Bach and Harnish 1979, pp. 121-22).
} 
clock in at 8.00 a.m.' is constitutive of an industrial bureaucracy. The first thing to note in response is that, if this is correct, the rule mentioned surely is only one of many rules that together are constitutive of industrial bureaucracy. Giddens notes that according to Max Weber control of time is one of the characteristics of bureaucracy, which explains the importance that documents have within a bureaucracy. Documents are 'both records of the past and prescriptions for the future' (Giddens 1984, p. 152). Although characterizations such as this one may be correct, they are too general to fit the counts-as locution. Institutional bureaucracy is not a status function to which deontic powers are attached as such. It may well involve such status functions. Giddens mentions double-entry bookkeeping as a device for controlling time that is characteristic of bureaucracies. This is certainly an institution that involves status functions of the kind Searle is concerned with (think, for instance, of bookkeepers and their deontic powers). However, the idea that industrial bureaucracy is an institution as such cannot be explicated in terms of rules that have the syntax of the counts-as locution.

This is unsurprising given Searle's concerns. The notion of an industrial bureaucracy operates at another level of abstraction than the institutions he is concerned with. He recognizes this when he notes that the kinds of institutions he focuses on are not on a par with institutions such as science, religion, and education. $\mathrm{He}$ describes these as 'massive forms of human practices around certain subject matters that do not as such carry a deontology' (Searle 2006a, p. 28). This implies that there are no rules that fit the counts-as locution that are characteristic of such large-scale institutions as such. Does this rule out that there are rules that are constitutive of these practices? Perhaps not. But it appears that, if we accept this, we must recognize that the word 'constitutive' is used here in a sense different from that involved in rules that fit the counts-as locution. The claim is that certain regulative rules are constitutive of particular practices, which means, roughly, that the relevant practices would not exist if it were not for these rules. This does not involve an explicit assignment of a status function.

Consider etiquette. Searle regards the rules of etiquette as paradigmatic cases of regulative rules that are not constitutive rules. Nevertheless, it seems undeniable that in some sense our practices of etiquette form an institution. It is, after all, a normative system that structures our social interactions. Consider an example of a rule of etiquette that Searle offers: 'When cutting food, hold the knife in the right hand.' (1969, p. 34). This is not a constitutive rule in the strict sense of the term. Although violating it is impolite, if not rude and boorish, one does not have any deontic powers just in virtue of the fact that the rule applies. Nevertheless, it may be that this rule together with some others is constitutive of the practice of etiquette in the looser sense mentioned earlier: this practice would not exist if it were not for those (regulative) rules.

The upshot is that Gidden's criticisms leave the distinction between constitutive and regulative rules intact. Although it may be that constitutive rules indirectly regulate our classificatory practices, they differ from regulative rules in that their formulations do not specify any obligations. Similarly, although it may be that regulative rules can in some sense be constitutive of our practices, they do not introduce new deontic powers that are characteristic of large-scale institutions of the 
kind Giddens mentions. I shall argue below that both of these conclusions need to be qualified (see the beginning of Sect. 3 and the end of Sect. 4). How exactly can only be appreciated after I have introduced the notion of a status rule and after I have discussed the role that language might play in relation to (other) institutions.

\subsection{First-Order and Second-Order Rules}

Ransdell (1971) distinguishes between two aspects of institutional terms: connotation and import. Roughly speaking, connotation concerns the descriptive conditions that have to be met in order for an institutional term to apply, while its import pertains to what can and cannot be done once those conditions are met. Using baseball as his example, Ransdell maintains that 'the application of the gameterm 'Bat' to a given object connotes that the object has a certain size, shape, construction, etc., but the import of the term concerns what can and cannot be done with the object in question within the game, as, e.g., it can be used to Swing at the Baseball by a Batter but cannot be used by a Baseman to trip a Runner, etc.' (ibid., p. 388). He argues that Searle focuses on the connotation of institutional terms at the expense of their import. The point is not that Searle is unaware of the import of such terms. Searle writes in fact:

[W]ithin systems the phrase which is the $Y$ term will not in general simply be a label. It will mark something that has consequences. Thus "offside", "homerun", "touchdown", "checkmate" are not mere labels for the state of affairs that is specified by the $X$ term, but they introduce further consequences by way of, e.g., penalties, points, and winning or losing. (1969, p. 36)

Instead, the point is that he does not fully integrate this aspect in his account of constitutive rules. Ransdell concludes that '[i]n view of the fact that none of this is brought out in a general way, there is reason to doubt that Searle fully recognized the significance of the "consequences" he mentions' (1971, p. 390).

Ransdell proposes an alternative conception of constitutive rules, the form of which is ' $X$ counts as $Z$ ' rather than ' $X$ counts as $Y$ in $C$ '. $Z$-terms are expressions of the import of institutional terms. Constitutive rules of this kind establish a direct connection between connotation and import. An example Ransdell provides is this: " "Allowing four Balls to pass while one is Batter counts as being henceforth subject to the following rules: __, "the list of rules which are then specified being, of course, those which apply to a Runner on First Base.' (Ibid.). The important thing to note is that the term 'runner on first base' does not appear in this rule (nor 'being walked' or 'being on first base'). This is why Ransdell goes on to note that 'the game-term is in principle eliminable from the description of the game altogether' (ibid.). Eliminating one game-term leaves many others (think of 'batter' and 'pitcher'). However, the idea is that in principle all of them can be eliminated one by one. The outcome of this process is a set of rules formulated in terms of connotation and import only. The upshot is that game terms do not play an essential role in the formulation of rules that constitute the relevant game. The same seems to hold for institutional terms in general. Ransdell concludes from this that 'aside from its 
(replaceable) function of linking connotation with import, the function of [terms such as 'bat'] in the game is merely mnemonic and practical' (ibid.). ${ }^{3}$

In Sects. 3 and $4 \mathrm{I}$ argue against this that, even though game terms and institutional terms generally can indeed be eliminated from the systems of rules in which they occur, they do have ontological significance in the sense that they often succeed in referring to institutional entities. Here I want to focus on what Ransdell says about rules that do employ institutional terms. Ransdell draws a distinction between first-order and second-order rules. First-order rules specify the import of institutional terms, which means that they 'prescribe mandatory or permissible behavior with or by the objects or persons to which they are applied' (ibid., p. 389). Second-order rules are the $X$ counts as $Z$ rules discussed earlier. Ransdell adds that a rule of this kind 'really expresses a second-order rule relating the satisfaction of a certain set of conditions [those specified in the $X$-term] to the applicability of a set of first-order rules' (ibid., p. 390; emphasis in original). According to this proposal, second-order rules include a formulation of the relevant first-order rules from which the institutional terms have been eliminated.

\subsection{Constitutive Rules and Status Rules}

The main message that I take away from Ransdell's critique is that what he calls 'import' does not play an explicit role in constitutive rules as they are to be formulated on Searle's account of them, even though import is of crucial importance for understanding the nature of institutions. It can, however, be incorporated in an account of institutions in a way that is different from Ransdell's proposal. Given that $Z$-terms specify the import of institutional terms, Ransdell's first-order rules link $Y$-terms with $Z$-terms. Second-order rules link $X$-terms with $Z$-terms directly. In this way, there is no longer any need to use institutional terms. The consequence of this conception of second-order rules is that first-order rules become redundant. For my purposes this is unsatisfactory. Given the goal of developing an ontology of institutional reality, it would be better if we hold on to the terms that (purport to) refer to institutional entities. What I propose to do is to develop a conception of how $Y$-terms relate to $X$-terms on the one hand, and to Z-terms on the other. As Searle's original counts-as locution links $X$-terms to $Y$-terms, I suggest complementing such $X Y$-rules with Ransdell's first-order rules, which link $Y$-terms to $Z$-terms. For reasons to be explained below I call such $Y Z$-rules 'status rules'. In other words, the

\footnotetext{
3 Sometimes it seems as if Searle has come to accept Ransdell's point. In response to criticisms voiced by Smith (2003) he argues against the idea that constitutive rules 'give us necessary and sufficient conditions for the application of social concepts' (Searle 2003, p. 300). He goes on to argue the following: 'For me the formula $X$ counts as $Y$ in $C$ is intended as a useful mnemonic to remind us that institutional facts only exist because people are prepared to regard things or treat them as having a certain status that they cannot perform solely in virtue of their physical nature. ... The formula is a simple summary of a complex thought.' (Ibid., p. 301). I believe there is more to constitutive rules than this. The proposal I go on to defend in the main text implies that a constitutive rule specifies conditions that are necessary and sufficient for the application of the relevant institutional status as it is realized in the context at issue.
} 
proposal is to combine Searlean constitutive rules with status rules in order to explicitly incorporate the normative dimension of institutions in the rules used for conceptualizing them. ${ }^{4}$

As we saw, Ransdell takes $Y Z$ or status rules to prescribe permissible or mandatory behavior. This suggests a close connection to Searle's notion of deontic power, which encompasses rights, permissions, and obligations. According to Searle $Y$-terms refer to status functions and such functions come with deontic powers. I suggest using the term 'status' rather than 'status function'. The term 'power' can be used to express anything that Searle tries to capture by using the term 'function' in relation to statuses, or so it seems to me. ${ }^{5}$ To be sure, it is quite intuitive to use the term 'function' in relation to an institution such as money. One of the functions of money is that it can be used as a means of exchange, which means that it facilitates or enables actions, in particular exchange of goods and services without the use of barter. However, the same idea can be expressed using the term 'power': money can be said to give people the power to perform the action mentioned. This usage of the term 'power' is well established within the philosophy of law. Powers form one of the four core rights distinguished in the Hohfeldian classification of rights, the others being privileges, claims, and immunities (see Wenar 2005). Although the kind of power that money provides does perhaps not coincide with the kind of power the Hohfeldian notion captures, they are closely related. I suggest using the term 'normative attribute' for all those features of statuses that Searle tries to capture with both the term 'status function' and the term 'deontic power'. The idea, then, is that $Y Z$ or status rules explicate the normative attributes that come with having a particular status. ${ }^{6}$

$X Y$ or constitutive rules specify the conditions that have to be met within a particular context in order for something to have the relevant status. The imposition of a status requires collective acceptance. This idea can be used to develop the notion of a constitutive rule beyond the characterization Searle has provided (recall that the proposal is to complement constitutive rules with status rules; they are not meant to replace them). His use of the phrase 'counts as' can be taken to suggest dependence on collective acceptance. The idea is, roughly, that if an $X$ counts as a $Y$ it is in fact a $Y$ because it is collectively accepted that it is a $Y$, or rather because

\footnotetext{
${ }^{4}$ Conte (1988) draws a similar distinction. However, he regards both kinds of rules as constitutive rules. On my view only $X Y$-rules are constitutive rules. Below it will become apparent that I take a constitutive rule to be a rule that explicates the constitution base of an institutional status. Status rules concern the practical significance of such statuses. This interpretation and the elaboration that I go on to provide in the main text also distinguish my proposal from Conte's.

5 The term 'function' is often used in relation to institutions in order to capture features of institutions of which the participants need not be aware. In Marxist conceptions of religion, for instance, it functions to pacify the toiling masses (Marx famously took religion to be the opium of the people). In light of this rather common usage of the term 'function' it makes sense to do without the term 'status function'. If the argument in the main text is correct, hardly anything speaks in favor of using the term in the way Searle does.

6 Those who are interested more in normative matters than in ontological ones might prefer to use the term 'power-conferring rules' for constitutive rules and 'power-specification rules' for status rules. The terms 'power-conferring rule' and 'power-conferring norm' are used in legal philosophy in a closely related sense (see Hart 1961 and Raz 1975).
} 
things of that kind are $Y$ s. As long as we appreciate this dependence on collective acceptance, the structure of constitutive rules can simply be taken to be: In $C, X$ is $Y$ (rather than $X$ counts as $Y$ in $C$ ). This amendment serves to explicate the intricate connection Searle sees between counting as and collective acceptance.

It is at this point that the notion of constitution becomes relevant. Constitution is a relation that obtains, for instance, between a statue and the piece of marble of which it is made. Baker $(1997,2000,2007)$ argues that a particular piece of marble constitutes Michelangelo's David because it bears a suitable relation to the art world. Without that relation, the piece of marble would not constitute a statue. Similarly, a piece of paper constitutes money only if it occurs in the appropriate circumstances. This feature of the constitution relation is reflected in the proposed formulation of constitutive rules: (only) in $C$, an $X$ constitutes a $Y$. Thus, we can say that the $X$-term specifies the constitution base of the concomitant status (the term 'constitution base' should be understood in analogy to the term 'supervenience base').

Although it is a relation of unity, constitution is distinct from identity. The fact that an entity that is $X$ constitutes an entity that is $Y$ only when the entity that is $X$ occurs in context $C$ already entails that the relation between the two entities cannot be identity. As no entity can bear such a context-dependent relation to itself, constitution is irreflexive. Entities at a particular level are always constituted by entities at a lower level, which are often constituted by entities at yet a lower level. This entails that constitution is asymmetric and transitive. It is important not to be mislead by the surface structure of ' $X$ is $Y$ ' in the proposed formulation of constitutive rules. It is to be read as shorthand for 'an entity that is $X$ constitutes an entity that is $Y^{\prime}$. Goldman claimed that the relation of level-generation is irreflexive, asymmetric, and transitive (1970, p. 21). The status account of institutions preserves this insight. Hence, it is committed to Goldman's fine-grained account of actionindividuation. This means that, for instance, extending one's arm out of the window is an action that is distinct from signaling a turn in the sense that the latter is constituted by the former.

This is another respect in which the status account differs from Searle's conventional generation account. Searle rejects the idea that there are different levels in reality. He argues that 'we do not need to postulate any separate or mysterious ontological levels in order to describe all of the facts' (Searle 2006b, p. 43). ${ }^{7}$ Related to this, he does not accept the idea that constitution is a relation that is distinct from identity. This is suggested by the fact that he rejects the idea that corporations are constituted by (collections of) individuals on the basis of the observation that 'the corporation itself is not identical with any physical object or any person or set of persons', and by the fact that he denies that 'there is an $X$ that counts as the corporation' (2006a, p. 24; see also 2003, p. 305). That corporations are not identical to (collections of) their members follows from the fact that they can outlive them. This forms no obstacle to accepting the claim that corporations are

\footnotetext{
7 Elsewhere he claims that he distinguishes seven different levels (Searle 2003, p. 304). As I shall explain in more detail below, these are not different ontological levels, but different levels of description.
} 
constituted by (collections of) people as long as one recognizes that constitution is distinct from identity. ${ }^{8}$

The thesis that constitutive rules pertain to statuses and that statuses are to be understood in terms of status rules forms the core of what I call 'the status account of constitutive rules'. Let me illustrate this using money and property as examples. The status rule of money is: money is a means of exchange. 'Money' is the $Y$-term, and 'means of exchange' is the $Z$-term, as it is the normative attribute that is characteristic of the status of money (what Ransdell calls 'import'). Perhaps this status rule applies universally in the sense that it is true independent of context. The constitutive rule that is associated with it, however, depends on a particular context. As indicated above, the following counts-as rule can be formulated for money in the United States: 'Bills issued by the Federal Reserve $(X)$ count as money $(Y)$ in the United States $(C)$.' In my preferred format this rule reads as follows: In the United States, bills issued by the Federal Reserve are money. As such a rule is indeed in force, it is collectively accepted within the context specified (it is accepted by the relevant institutions whose authority in turn depends on collective acceptance by the public).

Turning to the second example, the status rule for property explicates the rights involved in that status, notably the right of use, the right of exclusion, and the right of transfer. As these rights are usually tied to a particular person, it is easier to formulate the status rule for ownership: to be the owner of an object is a matter of having the right of use, the right of exclusion, and the right of transfer insofar as that object is concerned. Anything that is owned by someone is that person's property. Now, the conditions that have to be met for something to be someone's property depend on context and they are specified in the constitutive rule that is appropriate to the relevant context. Which conditions apply depends on many factors, not all of which will be dealt with here. They depend, for instance, on the kind of object that someone owns. Whereas paying for it suffices to make the purchaser the owner of a bar of chocolate, acquiring ownership of a house is more cumbersome and will usually involve a notary public. Moreover, instead of buying something, one can become its owner by inheriting it. A system of property rules will be a complex one, as it has to take these factors (and many more) into account. Note that the status rule of property is not universal. In the case of a piece of land, for instance, ownership does not always involve the right of exclusion. Sometimes the public should have access to the land to walk over it. Nevertheless, the differences between contexts appear to be much smaller than in the case of constitutive rules. And this holds for most statuses.

An important difference between the status account and the conventional generation account of constitutive rules is that the former encompasses more than the preconditions for the existence of institutional entities, the conditions that shed light on how institutional entities come about and are maintained. In addition to this, it explicates what such entities are in terms of status rules. The fact that shells are

\footnotetext{
${ }^{8}$ See Hindriks $(2008,2009 a)$ for more elaborate discussions of this issue. There I criticize the idea that some statuses are so-called 'free-standing $Y$-terms' — statuses without a physical realization-an idea that was proposed by Smith's (2003) and that has subsequently been embraced by Searle.
} 
used as money in one context and pieces of paper in another is, of course, very important for the functioning of the institution of money in those contexts. The fact that money is a means of exchange, however, concerns the very nature of money. Starting from Ransdell's criticism of Searle that he does not do justice to the import of institutional terms, I have suggested adding status rules to constitutive rules in order to incorporate the fact that at bottom institutional reality is a matter of normative attributes into the rules employed for understanding the nature of institutions.

\section{A Linguistic Distinction?}

Just as Giddens, Warnock (1971) maintains that all rules are regulative. We are now in a position to appreciate another way in which constitutive rules do indeed bear on the regulation of behavior, albeit, just as before, only indirectly. Status rules regulate directly, because their formulations specify powers, rights, and obligations: they explicate the normative attributes that are characteristic of a particular status. Constitutive rules contain the conditions that have to be met in a particular context for a certain status to be instantiated. If a constitutive rule is collectively accepted and its conditions are indeed met, the relevant status will indeed be instantiated. This in turn means that the associated status rule is in force as well. As a consequence, constitutive rules play a regulative role indirectly.

The only exception appears to be the purely honorific cases that Searle distinguishes: 'There is an interesting class of exceptions to the claim that all institutional facts involve power. Some institutional facts involve pure status with no further function. These are the cases where the status is purely honorific.' (1995, p. 96; see also pp. 101-02). These statuses involve no status rules, and they have only symbolic significance. So except for constitutive rules that concern purely honorific statuses, constitutive rules indirectly regulate our behavior through the status rules to which they are related. They do not regulate directly, because the new normative attributes figure not in them but in the relevant status rules.

In contrast to Giddens, Warnock allows for the possibility that only some rules are constitutive. He explicates this as follows: '[T]here is only sometimes a special term for compliance with or breach of a rule, into the 'sense' of which the rule essentially enters' (Warnock 1971, p. 37). He goes on to say that 'it is clear that there always could be such special terms' adding that 'it is often more or less accidental whether there actually are or not' (ibid., pp. 37-38). In effect, Warnock claims that the distinction between constitutive rules and regulative rules is merely a linguistic rather than an ontological one. David-Hillel Ruben provides a similar critique of the distinction:

Call an action description that entails the existence of rules a 'rule-involving action description'. What Searle provides is an account of two different types of action descriptions, namely rule-involving and non-rule-involving ones. Just as actions are intentional or nonintentional, basic or nonbasic, only relative to a description, so too actions are not rule-involving or non-rule- 
involving per se, but only relative to a description. ... This seems to me to be all there is to the constitutive v. regulative rule distinction. (1997, pp. 444-45)

Again, the suggestion is that the distinction between two kinds of rules is at bottom merely a linguistic difference, constitutive rules allowing for different descriptions of actions than regulative ones. ${ }^{9}$

This criticism can be countered in two ways. First, one can argue that it is a linguistic distinction, but that language matters to ontology. If it does in the requisite way, the rules that introduce new institutional terms are partly constitutive of institutional entities. Second, one can argue that at bottom it is not a linguistic distinction, or, if it is a linguistic distinction, it is not essential to the existence of institutional entities. I shall defend a version of the second alternative. Before doing so from Sect. 3.2 onwards, I shall argue that Searle can plausibly be taken to defend a version of the first alternative.

\subsection{Searle on Institutions and Language}

As is evident from his work in the philosophy of mind and language, Searle (1969, 1983 , 1999) takes thought to be prior to language. More specifically, he takes linguistic meaning to be 'a form of derived intentionality' (Searle 1999, p. 141). This would be consistent with ascribing hardly any or no role at all to language insofar as the constitution of institutions is concerned. On his conception of them, social facts do not depend on language, as is suggested by the following passage: '[A] social fact is simply any case of collective intentionality involving two or more animals.' (Searle 2003, p. 304). However, Searle takes institutional facts to depend on language, as is clear from how the passage mentioned continues: 'Institutional facts are more interesting, because they involve a deontic component, and with that deontic component comes the requirement of language.' (Ibid.). An immediate problem of this view appears to be that, as Searle recognizes, language is an institution itself. The implication seems to be that language presupposes language, which makes no sense. Searle's resolution of this problem is to regard language as the most fundamental institution that is presupposed by all others: 'Language is the presupposition of the existence of other social institutions in a way that they are not the presupposition of language. This point can be stated precisely. Institutions such as money, property, government and marriage cannot exist without language, but language can exist without them.' (2006a, p. 14; see also the section 'Does Language Require Language?' in 1995, pp. 72-76). According to Searle, all institutions other than language presuppose language. By excluding language from

\footnotetext{
9 Warnock's suggestion as to what exactly the linguistic difference between the two kinds of rules could amount to is at best partially correct. As we just saw, he claims that 'there is only sometimes a special term for compliance with or breach of a rule, into the 'sense' of which the rule essentially enters' (Warnock 1971, p. 37). This characterization may be adequate for some status terms, for example for 'thief'. A thief is someone who violates someone's property rights in the sense of taking something away that is not hers to take. However, the characterization does not work for many other status terms. Terms such as 'money', 'marriage', and 'president' are all terms the application of which does not involve compliance with or breach of a rule in the sense of obeying or violating a regulation directly. Instead, they specify the normative attributes associated with these statuses, and they can at most be violated indirectly.
} 
his claim about the language-dependence of institutions, he blocks the looming regress. In this way he can coherently take language to be essential for institutional ontology. ${ }^{10}$

Below I shall argue that Searle's argument for the language-dependence of institutions is not convincing. In order to be fair to him, I need to spend some time on uncovering what exactly Searle has in mind. His argument for the importance of language depends on his characterization of status functions. He claims that in contrast to causal functions, such as the functions of technical artefacts, status functions go beyond the physical features of the entities on which they are imposed. They are the sort of things that are constituted by agreement or collective acceptance, and the physical features of the relevant entities do not by themselves suffice for performing the functions (Searle 1995, p. 44). Because of this, we need language to represent those functions: '[T]here can be no prelinguistic way to represent the $Y$ element because there is nothing there prelinguistically that one can perceive or otherwise attend to in addition to the $X$ element, and there is nothing there prelinguistically to be the target of desire or inclination in addition to the $X$ element.' (Ibid., p. 68). Just a page later he returns to this and claims: 'Because the $Y$ level of the shift from $X$ to $Y$ in the creation of institutional facts has no existence apart from its representation, we need some way of representing it, because the $Y$ element has no natural prelinguistic features in addition to the $X$ element that would provide the means of representation. So we have to have words or other symbolic means to perform the shift from the $X$ to the $Y$ status.' (Ibid., pp. 69-70).

Now, this passage can easily be taken to mean that the referents of status terms, such as money, would not exist if it were not for those very same status terms. Searle, however, makes it clear that his view does not carry this strong requirement:

Money is only money if people think that it is money; a game is only a game if people think that it is a game. But it is impossible for us to have these thoughts without a certain sort of vocabulary. It is not necessary to have the actual word money or some synonym of it, but there has to be a vocabulary appropriate for buying, selling, and exchange generally for us to be able to manifest the collective intentionality which invokes the constitutive rules of private property and the exchange of property in return for money. (1991, pp. 342-43)

So the claim is that we need a vocabulary to refer to some status functions but not necessarily to all (see also Searle 2007, p. 91). One might want to suggest that, on Searle's view, language only plays a pragmatic role in relation to institutions. Searle takes language, for instance, to be a prerequisite for having thoughts of a certain complexity. Perhaps he believes a special vocabulary is needed only because of the

\footnotetext{
${ }^{10}$ Searle has changed his mind on this issue since 1969, as he has recently acknowledged: 'It is often said, and indeed I have said it myself, that the primary function of language is to communicate, that we use language with other people, and, in a limiting case, to communicate with ourselves in our thinking. But language plays an extra role, which I did not see when I wrote Speech Acts (1969), and that is that language is partly constitutive of all institutional reality. In order that something can be money, property, marriage, or government, people have to have appropriate thoughts about it. But in order that they have these appropriate thoughts, they have to have devices for thinking those thoughts, and those devices are essentially symbolic or linguistic.' (2004, p. 95).
} 
complexity of institutional phenomena. A consideration that he addresses explicitly is the role that communication plays in this context. Searle argues that the communicative function of language is important in relation to institutions, because constitutive rules need to be 'publicly available' as 'the nature of status functions requires that they be collectively recognized in order to do their work' (2007, p. 92). The role of language goes beyond this, however, as is implied by the following passage (see also note 10): '[W]here status functions are concerned, language and symbolism ... are partly constitutive of the very phenomena described.' (Ibid., p. 93).

Institutions do not require full-blown languages, but they do require linguistic representation. Searle considers 'cultures that have not evolved full-blown human languages' and maintains that in such cases 'the $X$ term itself is used to symbolize the $Y$ status' (1999, p. 155). This might make one wonder whether linguistic representation is really needed. Would mental representation not suffice? I shall argue that it would. Searle, however, takes the symbolization involved in status function ascription to be linguistic: '[T] o the extent that we use the $X$ term to represent the $Y$ status, we are using it symbolically, we are using it as a linguistic device.' (Ibid.; emphasis in original). The key idea that ties together all these passages in Searle's work is that there can be no institutions without linguistic representation. Further confirmation for this claim is provided by the following passage: 'I believe that language is the fundamental human institution in the sense that other institutions, such as money, government, private property, marriage, and games, require language, or at least language-like forms of symbolism, in a way that language does not require the other institutions for its existence.' (1999, p. 153; emphasis added).

As indicated above, the argument for the constitutive role of linguistic representations is that in the case of institutional entities there is no reality independent from our representations of them. In Searle's words, we need 'this basic symbolizing feature of language ... [b]ecause there is no way to read off the status function $Y$ just from the physics of the $X^{\prime}$ (1999, p. 154). A more elaborate version of the argument can be found in the following passage:

The reason that language is constitutive of institutional facts, in a way that is not constitutive of brute facts, or other sorts of social facts, or intentional facts in general, is that the move from $X$ to $Y$ in the formula $X$ counts as $Y$ in $C$ can only exist insofar as it is represented as existing. There is no physical feature present in the $Y$ term that was not present in the $X$ term. Rather the $Y$ term just is the $X$ term represented in a certain way. (Searle 2007, 93-94)

The problem with this argument is that it only establishes the importance of representation, while it fails to show that linguistic representations are needed. Searle claims that 'the move that imposes the $Y$ function on the $X$ object is a symbolizing move' (1995, p. 71). But he has not provided us with a reason why mentally representing the $X$ object as being an object that has function $Y$ (or, in my terminology, an object that is $X$ being an object that also has status $Y$ ) does not suffice.

Searle maintains that insofar as status functions are concerned 'there must be some device for representing them ... some symbolic device', and goes on to illustrate this in terms of the institution of the presidency: 'In order that Bush can be 
President, people must be able to think that he is President, but in order that they be able to think that he is President, they have to have some means for thinking that, and that means has to be linguistic or symbolic.' (2007, p. 94). This is perhaps Searle's most concrete defense of the importance of linguistic symbolization, but it does not rule out that mental representations might be able to do the job. We can have thoughts of non-existing objects, such as people with six arms or unicorns, without using language. More pertinent to the case of institutions is that we can have thoughts about the deontic powers or normative attributes that affect the parameters of our interactions without a special vocabulary for institutional entities (see also Sect. 2 of Hindriks 2009b). Language does not need to play a direct role in their constitution.

Searle's argument fails to rule out the claim that institutional facts depend on non-linguistic collective beliefs or other collective attitudes pertaining to deontic powers. This is problematic because it implies that the criticism that the distinction between constitutive and regulative rules is merely a linguistic one has not been disarmed. More needs to be said in order to support the idea that the notion of a constitutive rule is useful for understanding the ontology of institutions. The problem is all the more pressing because Searle claims that 'something is a social object only under certain descriptions and not others' (2003, p. 302). This could be taken to suggest that Searle sides with Warnock and Ruben after all. There may be different levels of descriptions, but they do not match distinct levels in reality (see Sect. 2.3 and note 7). The upshot is that an adequate development of the claim that insofar as institutions are concerned language matters to ontology is still lacking. Since Searle's argument for language-dependence turns out to be flawed anyway, I suggest exploring the alternative that institutions are constituted in part by mental representations.

\subsection{Institutions Without Language}

On the status account of institutions introduced in Sect. $2.3 Y$-terms refer to statuses, statuses involve normative attributes, and which normative attributes are involved in a particular status is determined by the relevant status rule. Consider for instance the right of use of a good, one of the attributes that is characteristic of property rights. It seems perfectly possible to collectively accept that someone has the right of use over a house, say. And it may be such collective acceptance that is constitutive of that right, independently of whether the people involved use language specific to the statuses involved.

Suppose that institutions do indeed only require mental representations and do not essentially depend on linguistic ones. Would it make an ontological difference whether we collectively accepted a regulative rule or a constitutive rule? As I shall argue below, it does not. This does not mean, however, that there are no statuses when the only rules that are accepted are regulative rules. Instead-and perhaps surprisingly - it means that statuses are already in place when a regulative rule is collectively accepted. This in spite of the fact that no rule has been accepted in which a term figures that refers to that status. 
Consider a prototype of our institution of property, property*. The only right involved in this institution is the right of (exclusive) use. In the proto-society we consider, society $P$, this right has only been introduced with respect to land and the only condition one has to meet in order to possess a piece of land is that one be the first to occupy it, for instance, by building a fence around it. Based on this information, we can formulate a constitutive rule and a status rule for the institution of property* in the society under consideration. The constitutive rule is: In $P$, a piece of land is someone's property* exactly if s/he is (was) the first to occupy it. The status rule is: Whoever's property* a piece of land is has the right of its (exclusive) use. My suggestion now is that the ontology is exactly the same if the members of $P$ accept the constitutive rule formulated, as compared to the situation in which they accept, and hence mentally represent, the following regulative rule: If one is the first to occupy a certain piece of land, one has the right to its exclusive use. More specifically, the status of a piece of land being someone's property* obtains just as well in the latter case as in the former (cf. Lewis 1969, pp. 47-48). The members of $P$ need not have accepted a rule containing the term 'property*' in order for them to have property*. Of course, a sociologist or anthropologist can study their institutional practices and come to use this term to describe one of the statuses involved in them. But this is in no way necessary.

In a sense my argument is the reverse of Searle's. Searle maintains that we need the relevant vocabulary for representing institutional reality in order for it really to exist. In contrast, my claim is that all kinds of statuses can exist without us having the vocabulary or even the concepts for representing them. All that is needed is concepts of modalities, such as powers, rights, and obligations, and actions- the material that figures in regulative rules and that could go into the specification of normative attributes involved in status rules.

In order to explain how this can be, it will be useful to explore the analogy between theoretical terms in science and institutional terms. In the case of theoretical terms in science, it has been argued that the fact that reductive definitions can be provided does not entail that such terms do not refer and that theoretical entities do not exist. Conversely, it might be that statuses exist even if no rules that introduce terms that refer to them figure in our language. In such a situation, the relevant reductive definitions could be constructed and the status terms they would define might in fact refer.

\section{The Definition of Institutional Terms}

As is well known, it has often been argued that theoretical terms in science, such as 'electron' and 'quark', do not refer. They are just theoretical constructs introduced for purposes of prediction. Famously, scientific realists such as Lewis (1983b) argued against this position that such terms do in fact refer. Now, if they do, theoretical entities exist and they already existed well before we introduced the terminology for talking about them. Institutional entities are of course constructed by human beings. However, Lewis' account of theoretical terms can be used to argue that such entities could exist even if there were no special terms that refer to 
them (nor special concepts under which they fall). All that is needed is that the roles the statuses play are in place. And, I argue, regulative rules suffice for this purpose. In a sense, the roles or statuses are implicitly introduced in the regulative rules.

Relying on ideas proposed by F. P. Ramsey and Rudolf Carnap, Lewis (1983b) argues that the new terms that a newly proposed scientific theory introduces can be explicated in terms that are understood beforehand. The way to do this is by eliminating the theoretical terms, replacing them by bound variables, and specifying the relationships that obtain between these variables according to the theory using terms that are independent of the theory. Because of its focus on such interrelationships Smith (1994, p. 45) calls this method for defining terms 'a network analysis'. In our case institutional terms are the terms to be explicated, while non-institutional terms belonging to our common-sense vocabulary form the terms that are understood independently. This part of our common-sense vocabulary includes terms referring to modalities, such as obligation, and (non-institutional) actions, as well as terms used for describing objects, persons, events, situations, and items belonging to other ontological categories on which statuses are imposed. Because of the interconnections between institutional terms, this procedure has to be applied to our complete institutional vocabulary all at once (or at least to large subcategories of it in case there are parts of institutional reality that are independent of one another). To define 'money' as 'that property that facilitates exchange of goods and services' will not do. The reason for this is that 'exchange' is itself an institutional term. The only way to understand what money is in non-institutional terms is by reducing all of our vocabulary related to buying, selling, property, and hence right of use, exclusion, and transfer (and perhaps all other institutional vocabulary) to non-institutional terms at the same time.

At this point, the reader might want to object that the exercise of defining institutional terms in terms of non-institutional ones only goes to show that institutional statuses do not actually exist. If we can do without the terminology, the thought would be, the idea that status terms refer to real entities is just a figment of our imagination. Quite the opposite is true. The analysis provided is to be combined with the substantive claim that there are indeed entities that stand in the specified relationships to one another. The fact that we can do without special names for them does not imply that they do not exist. Even in situations in which we do not use status terms, the statuses that figure implicitly in the regulative rules do exist. Before explaining this in further detail, let us consider how Lewis makes this point in relation to theoretical entities:

My proposal could be called an elimination of theoretical terms, if you insist: for to define them is to show how to do without them. But it is better called a vindication of theoretical terms; for to define them is to show that there is no good reason to want to do without them. They are no less fully interpreted and no less well understood than the old terms we had beforehand. ... I am also not planning to "dispense with theoretical entities." Quite the opposite. The defining of theoretical terms serves the cause of scientific realism. A term correctly defined by means of other terms that admittedly have sense and denotation can scarcely be regarded as a mere bead on a formal abacus. If it 
purports to name something, then if the theory that introduced it is true it does name something. (Ibid., pp. 78-79; emphasis added)

Thus, the aim of the exercise of defining theoretical terms by eliminating them is to show that the entities to which such terms refer are perfectly respectable.

Suppose all we had was a complex network of interrelated regulative rules that do not employ institutional terms. In such a situation, we could introduce institutional terms such as 'property*' in the way suggested above. And Lewis' method for defining or reducing such terms could be used in support of the claim that these terms refer to institutional entities.

As a matter of fact, we do use a large number of status terms and status concepts. This is very convenient, because it enables us to think about parts of institutional reality without having the whole network of regulative rules in mind, something that appears to be practically impossible. This is what Lewis has in mind when he writes the following about the rules of baseball:

The rules of baseball could in principle be formulated as straightforward directives concerning behavior [i.e. regulative rules], without the aid of definable terms for score and its components [i.e. constitutive rules]. Or they could be formulated as explicit definitions of the score function, the components of score, and correct play, followed by directives in which the newly defined terms occur [i.e. one sentence that is a conjunction of several constitutive rules and several status rules]. It is easy to see why neither of these methods of formulation has found favor. The first method would pack the entire rulebook into each directive; the second would pack the entire rulebook into a single preliminary explicit definition. Understandably averse to very long sentences, we do better to proceed in our more devious way. (1983a, p. 327)

The more devious way Lewis mentions at the end of this passage, I suggest, is to work with a combinations of constitutive and status rules, as was proposed in Sect. 2.3. This means that, rather than collectively accepting a proposition into which the entire rulebook of institutional reality is packed, we collectively accept the relevant constitutive rules. $^{11}$

The upshot of this discussion is that the distinction between constitutive rules and regulative rules is a linguistic one. However, rather than showing that the only difference that relying on constitutive rules makes is a difference in the description of our actions, as Ruben has it, it reveals that status terms refer to statuses, and that such statuses exist even if we have not introduced special terms for naming them. They are present implicitly in the regulative rules that we accept in such a situation. Pace Searle, institutional entities can exist without us having a special vocabulary for talking about them. Giddens turns out to be right after all when he claims that mere regulative rules, i.e. rules for action that do not employ (new) status terms, have a constitutive aspect. Although there are no rules specific to large-scale

11 I thank Frank Jackson for a helpful discussion on this topic. 
institutions such as industrial bureaucracy, particular regulative rules do introduce new deontic powers that are constitutive of institutions.

\section{Conclusion}

In Sect. 3 I suggested that the criticism voiced by Warnock and Ruben that the distinction between constitutive and regulative rules is merely a linguistic distinction can be countered in two ways. First, language might matter to ontology. If it does so in the requisite way, the rules that introduce new institutional terms are partly constitutive of institutional entities. Second, at bottom the distinction is not a linguistic one, or, if it is a linguistic distinction, it is not essential to the existence of institutional entities. I have defended a version of the second alternative. The first step in my argument consisted of the introduction of the notion of a status rule. The normative attributes that are characteristic of a particular status figure in the content of the relevant status rule. Constitutive rules contain the conditions that have to be met in a particular context for a status to be instantiated. Regulative rules have turned out to be rules that link those conditions directly to normative attributes. The crucial difference is that regulative rules do not introduce new status terms. Thus, the notion of a status rule was used to reveal that the distinction between constitutive and regulative rules is indeed a linguistic one.

Nevertheless, I have argued that there is an underlying reality that constitutive rules serve to make apparent. I made a case for this claim by turning Lewis' argument for the existence of theoretical entities on its head. He has argued that the fact that it is possible to formulate reductive definitions does not imply that the terms that are defined do not refer. In fact, he takes such definitions to 'serve the cause of scientific realism', as we saw in Sect. 4. I have argued that collective acceptance of regulative rules is all that is needed for institutions to exist. In such a situation, however, it is difficult to determine exactly which institutional entities exist. We would need to look at our own society as anthropologists, and introduce theoretical terms to describe the roles that people play, the statuses that objects have, and the normative import of certain kinds of events. The fact that participants do not use these theoretical terms themselves does not mean they do not refer. The regulative rules can be used to construct definitions of those terms. This will be a matter of transforming each regulative rule into a pair consisting of a constitutive rule on the one hand and a status rule on the other. The possibility that such definitions can be constructed in the way described above, I have in effect argued, serves the cause of institutional realism.

Acknowledgments I am grateful for helpful comments from the audiences at Collective Intentionality III, a conference held in Rotterdam in 2002, and those at the seminars of the Centre for Applied Philosophy and Public Ethics (CAPPE) in Canberra, Melbourne, and Wagga Wagga in 2003. I would also like to thank Uskali Mäki and Raimo Tuomela for the discussions we had on the topic of this paper, as well as for their detailed comments on drafts. Finally I would like to acknowledge two anonymous referees who provided comments that helped me to further improve the paper. 
Open Access This article is distributed under the terms of the Creative Commons Attribution Noncommercial License which permits any noncommercial use, distribution, and reproduction in any medium, provided the original author(s) and source are credited.

\section{References}

Anscombe, G. E. M. (1981/1958). On brute facts. In: The collected papers of G.E.M. Anscombe (Vol. 3, pp. 22-25). Oxford: Basil Blackwell.

Bach, K., \& Harnish, R. M. (1979). Linguistic communication and speech acts. Cambridge, MA: MIT Press.

Baker, L. R. (1997). Why constitution is not identity. The Journal of Philosophy, 94(12), 599-621. doi: $10.2307 / 2564596$.

Baker, L. R. (2000). Persons and bodies: A constitution view. Cambridge: Cambridge University Press.

Baker, L. R. (2007). The metaphysics of everyday life: An essay in practical realism. Cambridge: Cambridge University Press.

Boella, G., \& Van Der Torre, L. (2004). Regulative and constitutive norms in normative multiagent systems. In: D. Dubois, C. Welty \& M. A. Williams (Eds.), Principles of knowledge representation and reasoning. Proceedings of the ninth international conference, KR 2004 (pp. 255-266). Menlo Park: AAAI Press.

Conte, A. G. (1988). An essay on constitutive rules. In: Poznan studies in the philosophy of the sciences and the humanities (Vol. 11, pp. 251-257). Amsterdam: Rodopi.

Garcia, J. L. A. (1987). Constitutive rules. Philosophia, 17, 251-270. doi:10.1007/BF02455048.

Giddens, A. (1984). The constitution of society. Berkeley: University of California Press.

Gluër, K., \& Pagin, P. (1999). Rules of meaning and practical reasoning. Synthese, 117, 207-227. doi: 10.1023/A:1005162503125.

Goldman, A. I. (1970). A theory of human action. Englewood Cliffs: Prentice-Hall.

Grossi, D., Meyer, J.-J. C., \& Dignum, F. (2006). Classificatory aspects of counts-as: An analysis in modal logic. Journal of Logic and Computation, 16, 613-643. doi:10.1093/logcom/ex1027.

Hart, H. L. A. (1961). The concept of law. Oxford: Clarendon Press.

Hindriks, F. (2008). The status account of corporate agents. In H. B. Schmid, K. Schulte-Ostermann \& N. Psarros (Eds.), Concepts of sharedness-essays on collective intentionality (pp. 119-144). Frankfurt: Ontos Verlag.

Hindriks, F. (2009a). But where is the university? (mimeo).

Hindriks, F. (2009b). Language and society. In: I. Jarvie \& J. Zamora-Bonilla (Eds.), The SAGE handbook of the philosophy of social science (forthcoming).

Jones, A. J. I., \& Sergot, M. (1997). A formal characterization of institutionalized power. In E. G. Valdés, et al. (Eds.), Normative systems in legal and moral theory. Berlin: Duncker \& Humblot.

Lagerspetz, E. (1995). The opposite mirrors. An essay on the conventionalist theory of institutions. Dordrect: Kluwer.

Lewis, D. (1969). Convention: A philosophical study. Cambridge (MA): Harvard University Press.

Lewis, D. (1983a). Scorekeeping in a language game. In: Philosophical papers (Vol. I, pp. 233-249). Oxford: Oxford University Press.

Lewis, D. (1983b). How to define theoretical terms. In: Philosophical papers (Vol. I, pp. 78-95). Oxford: Oxford University Press.

MacCormick, N., \& Weinberger, O. (1986). An institutional theory of law. Dordrecht: Reidel.

Midgley, G. C. (1959). Linguistic rules. Proceedings of the Aristotelian Society, LIX, 271-290.

Ransdell, J. (1971). Constitutive rules and speech-act analysis. The Journal of Philosophy, 68, 385-399. doi: $10.2307 / 2025037$.

Rawls, J. (1955). Two concepts of rules. The Philosophical Review, 64, 3-32. doi:10.2307/2182230.

Raz, J. (1975). Practical reason and norms. London: Hutchinson.

Ruben, D. H. (1997). John Searle's the construction of social reality. Philosophy and Phenomenological Research, 57(2), 443-447. doi:10.2307/2953734.

Ruiter, D. (1997). A basic classification of legal institutions. Ratio Juris, 10(4), 357-371. doi: 10.1111/1467-9337.00066. 
Searle, J. R. (1964). How to derive "ought" from "is". The Philosophical Review, 73, 43-58. doi: $10.2307 / 2183201$.

Searle, J. R. (1969). Speech acts: An essay in the philosophy of language. Cambridge: Cambridge University Press.

Searle, J. R. (1983). Intentionality: An essay in the philosophy of mind. Cambridge: Cambridge University Press.

Searle, J. R. (1991). Intentionalistic explanations in the social sciences. Philosophy of the Social Sciences, 21, 332-344. doi:10.1177/004839319102100303.

Searle, J. R. (1995). The construction of social reality. New York: The Free Press.

Searle, J. R. (1999). Mind, language and society. London: Weidenfeld \& Nicolson.

Searle, J. R. (2003). Reply to Barry Smith. American Journal of Economics and Sociology, 62, 299-309.

Searle, J. R. (2005). What is an institution? Journal of Institutional Economics, 1, 1-22. doi:10.1017/ S1744137405000020.

Searle, J. R. (2006a). Social ontology. Some basic principles. Anthropological Theory, 6, 12-29. doi: $10.1177 / 1463499606061731$.

Searle, J. R. (2006b). Culture and fusion. Reply to D'Andrade. Anthropological Theory, 6, 40-44. doi: $10.1177 / 1463499606061733$.

Searle, J. R. (2007). Freedom \& neurobiology. Reflections on free will, language, and political power. New York: Columbia University Press.

Smith, B. (2003). The ontology of social reality. American Journal of Economics and Sociology, 62, 285299. doi:10.1111/1536-7150.t01-1-00012.

Smith, M. (1994). The moral problem. Oxford: Blackwell.

Tummolini, L., \& Castelfranchi, C. (2006). The cognitive and behavioral mediation of institutions: Towards an account of institutional actions. Cognitive Systems Research, 7, 307-323.

Tuomela, R. (2002). The philosophy of social practices. A collective acceptance view. Cambridge: Cambridge University Press.

Warnock, G. J. (1971). The object of morality. London: Methuen \& Co.

Wenar, L. (2005). Rights. In: E. N. Zalta (Ed.), Stanford encyclopedia of philosophy (plato.stanford.edu).

Williamson, T. (1996). Knowing and asserting. The Philosophical Review, 105(4), 489-523. doi:10.2307/ 2998423. 